\title{
Low-Cost Bio-Based Carbon Fiber for High-Temperature Processing
}

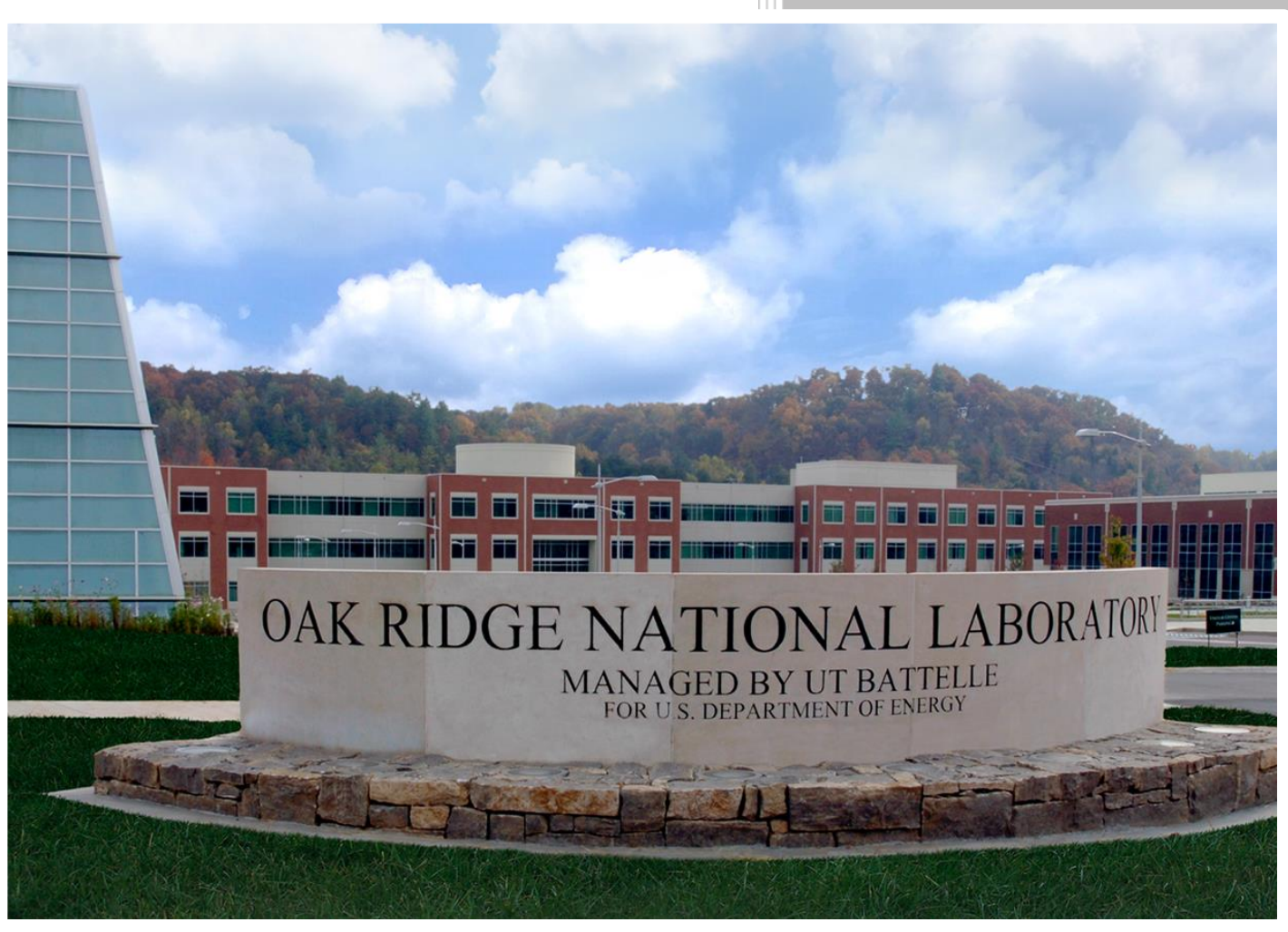

Amit K Naskar

Ryan M Paul

CRADA FINAL REPORT NFE-15-05807

Approved for Public Release. Distribution is Unlimited. 


\section{DOCUMENT AVAILABILITY}

Reports produced after January 1, 1996, are generally available free via US Department of Energy (DOE) SciTech Connect.

Website http://www.osti.gov/scitech/

Reports produced before January 1, 1996, may be purchased by members of the public from the following source:

National Technical Information Service

5285 Port Royal Road

Springfield, VA 22161

Telephone 703-605-6000 (1-800-553-6847)

TDD 703-487-4639

Fax 703-605-6900

E-mail info@ntis.gov

Website http://www.ntis.gov/help/ordermethods.aspx

Reports are available to DOE employees, DOE contractors, Energy Technology Data Exchange representatives, and International Nuclear Information System representatives from the following source:

Office of Scientific and Technical Information

PO Box 62

Oak Ridge, TN 37831

Telephone 865-576-8401

Fax 865-576-5728

E-mail reports@osti.gov

Website http://www.osti.gov/contact.html

This report was prepared as an account of work sponsored by an agency of the United States Government. Neither the United States Government nor any agency thereof, nor any of their employees, makes any warranty, express or implied, or assumes any legal liability or responsibility for the accuracy, completeness, or usefulness of any information, apparatus, product, or process disclosed, or represents that its use would not infringe privately owned rights. Reference herein to any specific commercial product, process, or service by trade name, trademark, manufacturer, or otherwise, does not necessarily constitute or imply its endorsement, recommendation, or favoring by the United States Government or any agency thereof. The views and opinions of authors expressed herein do not necessarily state or reflect those of the United States Government or any agency thereof. 
Advanced Manufacturing Office Materials Science and Technology Division

\title{
Low-Cost Bio-Based Carbon Fiber for High-Temperature Processing \\ Amit K Naskar \\ Kokouvi Akato \\ Chau D Tran \\ Oak Ridge National Laboratory \\ Ryan M. Paul \\ Xuliang Dai \\ GrafTech International Holdings Inc. \\ Brooklyn Heights, OH 44131
}

Date Published:

February 9, 2017

\author{
Prepared by \\ OAK RIDGE NATIONAL LABORATORY \\ Oak Ridge, Tennessee 37831-6283 \\ managed by \\ UT-BATTELLE, LLC \\ for the \\ US DEPARTMENT OF ENERGY \\ under contract DE-AC05-00OR22725
}

Approved for Public Release 


\section{Table of Contents}

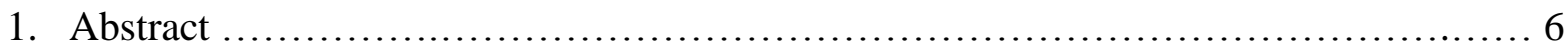

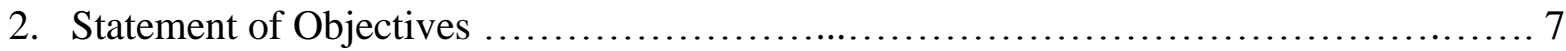

3. Benefits to the Funding DOE Office's Mission ......................................

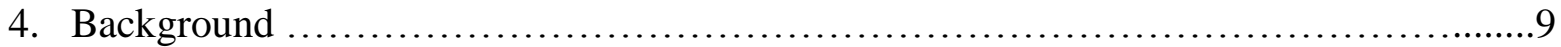

5. Technical Discussion of Work Performed ....................................... 14

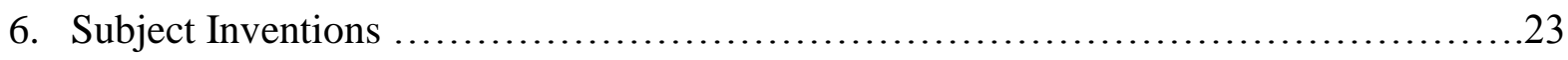

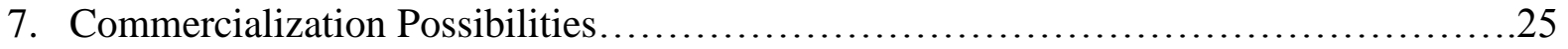

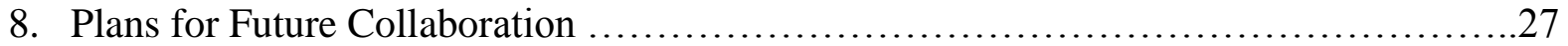

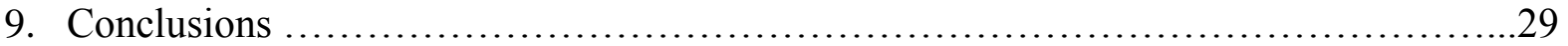




\section{LIST OF FIGURES}

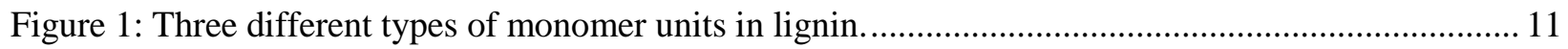

Figure 2: Example of intermonomer linkages and branching in lignin. .............................................. 11

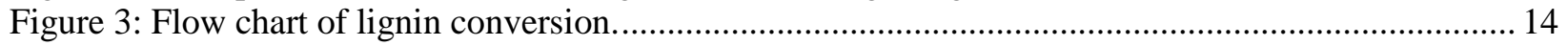

Figure 4: Stabilized lignin fibers samples. Images taken by GrafTech. .............................................. 16

Figure 5: Carbonized and milled (chopped) LBCF from two different types of lignin. Images taken

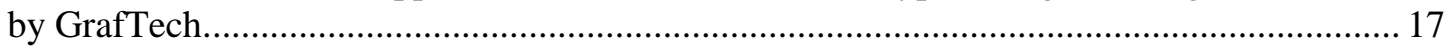

Figure 6: Chart compares two lignin-based carbon fiber cost models. Model A is original ORNL cost model as described in ORNL/TM-2013/54. Model B is cost model updated by GrafTech. In this chart the precursor costs includes lignin, lignin treatment, and melt blowing.

Figure 7: Chart demonstrates the predicted contribution of each processing step in LBCF to total estimated production cost.

Figure 8: Predicted sensitivity from cost model of fiber carbonization yield, precursor cost, and stabilization time. The midpoint is $\$ 5.00 / \mathrm{lb}$, and the size of the bars indicates that when taken by itself fiber yield has the largest relative effect, with precursor cost being the second largest effect, and stabilization time being the third.

Figure 9: Predicted effect from cost model showing influence of stabilization time. Plot shows predicted effect from cost model of stabilization time, assuming $45 \%$ carbon yield. The blue box shows the range of conditions to meet $\$ 5.00 / \mathrm{lb}$ estimated production cost.

Figure 10: Cost Model Breakdown

\section{LIST OF TABLES}

Table 1: Table highlighting top lignin samples............................................. 6

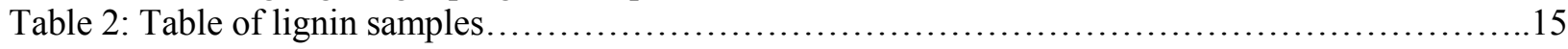

\section{ACKNOWLEDGEMENTS}

This CRADA NFE-15-05807was sponsored by the US Department of Energy Advanced Manufacturing Office (CPS Agreement Number 29316). Research sponsored by the U.S. Department of Energy, Office of Energy Efficiency and Renewable Energy, Advanced Manufacturing Office, under contract DE-AC05-00OR22725 with UT-Battelle, LLC. 


\section{ABSTRACT}

GrafTech International Holdings Inc. (GTI), worked with Oak Ridge National Laboratory (ORNL) under CRADA No. NFE-15-05807 to develop lignin-based carbon fiber (LBCF) technology and to demonstrate LBCF performance in high-temperature products and applications. This work was unique and different from other reported LBCF work in that this study was application-focused and scalability-focused. Accordingly, the executed work was based on meeting criteria based on technology development, cost, and application suitability.

The focus of this work was to demonstrate lab-scale LBCF from at least 4 different precursor feedstock sources that could meet the estimated production cost of $\$ 5.00 /$ pound and have ash level of less than $500 \mathrm{ppm}$ in the carbonized insulation-grade fiber. Accordingly, a preliminary cost model was developed based on publicly available information.

The team demonstrated that 4 lignin samples met the cost criteria, as highlighted in Table 1. In addition, the ash level for the 4 carbonized lignin samples were below $500 \mathrm{ppm}$. Processing asreceived lignin to produce a high purity lignin fiber was a significant accomplishment in that most industrial lignin, prior to purification, had greater than $4 \mathrm{X}$ the ash level needed for this project, and prior to this work there was not a clear path of how to achieve the purity target.

The lab scale development of LBCF was performed with a specific functional application in mind, specifically for high temperature rigid insulation. GTI is currently a consumer of foreignsourced pitch and rayon based carbon fibers for use in its high temperature insulation products, and the motivation was that LBCF had potential to decrease costs and increase product competitiveness in the marketplace through lowered raw material costs, lowered energy costs, and decreased environmental footprint. At the end of this project, the Technology Readiness Level (TRL) remained at 5 for LBCF in high temperature insulation.

Table 1: Table highlighting top lignin samples.

\begin{tabular}{|l|l|c|c|c|c|}
\hline \multicolumn{1}{|c|}{ ID } & \multicolumn{1}{|c|}{ Sample } & $\begin{array}{c}\text { Best Stabilization } \\
\text { Time To Date }\end{array}$ & Carbon Yield & $\begin{array}{c}\text { Estimated } \\
\text { Production Cost }\end{array}$ & $\begin{array}{c}\text { Ash } \\
\text { Level }\end{array}$ \\
\hline 1 & Modified HW organosolv & 3.0 hours & $44 \%$ & $\$ 4.99 / \mathrm{lb}$ & $200 \mathrm{ppm}$ \\
\hline 4 & Modified Indulin $®$ AT & 1.5 hours & $41 \%$ & $\$ 5.00 / \mathrm{lb}$ & $310 \mathrm{ppm}$ \\
\hline 5 & Modified Protobind TM 1000 & 1.8 hours & $42 \%$ & $\$ 5.00 / \mathrm{lb}$ & $380 \mathrm{ppm}$ \\
\hline DD & Modified Experimental SW organosolv & 2.5 hours & $44 \%$ & $\$ 4.94 / \mathrm{lb}$ & $480 \mathrm{ppm}$ \\
\hline
\end{tabular}




\section{STATEMENT OF OBJECTIVES}

The overall project goal was to develop lignin-based carbon fiber (LBCF) technology and demonstrate LBCF performance in high-temperature products and applications. One objective was to demonstrate that LBCF could be a direct replacement for higher-cost, foreign-sourced isotropic pitch and rayon carbon fibers (CF) currently used in GrafTech's commercial hightemperature insulation products. GrafTech manufactures several insulation products that were evaluated using LBCF, including GRI ${ }^{\mathrm{TM}}$ rigid insulation. LBCF had also been evaluated for felt insulation, which was increasingly an important component in insulation customer solutions, but was also made with foreign-sourced fiber. 


\section{BENEFITS TO THE FUNDING DOE OFFICE'S MISSION}

This project had important implications for manufacturing innovation and industrial energy efficiency. High-temperature insulation is used in energy intensive processes, such as in heat treating furnaces and in the manufacture of semiconductors, photovoltaic materials, and advanced ceramics that drive high-tech products. High-temperature insulation is also used in furnaces that heat treat carbon fibers that are processed into insulation.

Currently Asian suppliers dominate the insulation market in the USA and internationally; domestic insulation suppliers, such as GrafTech, need to increase their competitive advantage to continue to compete globally and keep up with customer demand for higher purity insulation and higher insulation efficiency. LBCF may have offered a true manufacturing innovation for insulation materials if the technical and commercial issues were overcome. In another application, low-cost LBCF can be very attractive; as reinforcement for graphite electrodes and pins and may have helped increase electric arc furnace (EAF) steel making productivity by increasing the lifetime of the electrode and pin. For activated carbon fiber filtration, a low-cost LBCF can enable more energy efficient heating ventilation and air conditioning (HVAC) systems. 


\section{BACKGROUND}

There is a current unmet need for a low-cost functional (i.e. non-structural) isotropic carbon fiber for applications such as insulation or filtration. Typically, either pitch or rayon fibers are used in these applications; however these fibers are foreign-sourced and are relatively high cost. Pitch fibers in particular have unstable pricing due to swings in petroleum price. Lignin-based carbon fibers (LBCF) could have been a direct substitute for pitch or rayon fibers within these applications. Not only would LBCF be a separate supply chain from pitch or rayon fibers that is decoupled from petroleum, but due to the low cost of lignin, the overall cost of LBCF could be $50 \%$ lower than current fibers. Furthermore, due to the unique structure of lignin, LBCF could not only be lower in price but could have a higher insulating value than pitch or rayon and help accelerate the next generation of insulation, to increase competitiveness and keep up with increasing customer demands for lower thermal conductivity insulation (enabling higher thermal efficiency). The current barrier was that the LBCF supply chain had not been established because the LBCF process, scalability, cost, properties, and applications had not been validated to enable a commercial decision to be made by either CF manufacturers or product manufacturers like GrafTech. There are several technical barriers that exist, and were addressed at the lab scale in this project, including the purity and melt spinnability of lignin precursors as well as stabilization time, which directly impacted cost and scalability.

Preliminary work performed by GrafTech and ORNL has shown the potential for LBCF in rigid insulation using GrafTech pilot scale equipment in GrafTech's Innovation and Technology Center (ITC). ${ }^{1}$ During that earlier DOE Advanced Manufacturing Office funded project, stabilized LBCF was shipped from ORNL to GTI's ITC where it was carbonized and made into two insulation prototype cylinders (18" diameter x 10" height). Thermal conductivity and strength properties of the insulation prototypes were acceptable compared to isotropic pitch fibers, although the ash target was not met. However, this work was preliminary in that it used one lignin source. Despite the preliminary nature of the work, GrafTech and ORNL showed that through its productive collaboration there is a promising path forward for LBCF and LBCF applications.

In ORNL/TM-2013/54, "Commercialization of New Carbon Fiber Materials Based on Sustainable Resources for Energy Applications" it is estimated that the production cost for lignin-based carbon fiber would be $\$ 4.22 / \mathrm{lb}$ if: (1) the lignin purchase price is $\$ 0.25 / \mathrm{lb}$, (2) treatment or purification is not required, (3) compounding and pelletizing is required, (3) fiber is melt blown in mat with areal density of $44 \mathrm{oz} / \mathrm{sq}$ yd $\left(1,500 \mathrm{~g} / \mathrm{m}^{2}\right)$, (4) stabilization time is 2 hours, (5) carbonization and heat treatment is performed in conventional furnaces, (6) yield is $45 \%$, and (7) carbon fiber production is 6250 tons/year. Furthermore, it was reported that a stabilization time of 10 hours or less should still result in $\$ 5 / \mathrm{lb}$ production cost. However, to date, a clear path to achieve the combinations of above assumptions is not apparent to GrafTech, as there are both technical challenges and scale-up challenges associated with them. These challenges are the reasoning for why the current project was focused on lab scale technical challenges, with future aim to scale-up, product evaluation, and further supply chain development. In addition, a more detailed analysis of the model assumptions and a sensitivity

\footnotetext{
${ }^{1}$ Eberle, Cliff, et al. "Commercialization of New Carbon Fiber Materials Based on Sustainable Resources for Energy Applications." Oak Ridge National Laboratory (2013).
} 
analysis of the parameters was performed to allow GrafTech to develop business cases and evaluate technical/market risk for using the lignin carbon fiber in its products, such as insulation.

\section{Applicable Literature}

It is widely recognized that carbon fiber cost is one of the barriers that limits its adoption in industrial applications. Since precursors are approximately $50 \%$ of production cost, justifiable work to reduce carbon fiber cost has focused on lower-cost precursors. Stabilization and carbonization heat treatment are about $16 \%$ and $23 \%$, respectively of production costs, based on the Kline and Company model. ${ }^{2}$

One of the potential lower-cost precursors is lignin, which has been investigated as a carbon fiber precursor since at least the 1960s. ${ }^{3,4,5}$ Lignin, which is a byproduct of the pulp and paper industry, could potentially be available in large volumes, although most lignin is not extracted from the processing stream and is instead burned for fuel. However, some percentage of lignin is extracted, and there is a limited supply chain and market for lignin as a dispersant and additive. Higher value applications are necessary to accelerate lignin extraction, which is becoming increasingly important for biorefineries that generate more lignin than needed for fuel. ${ }^{6,7}$

Although there have been a number of reports of successful lignin-based carbon fiber production at the lab scale, lignin-based carbon fibers are not currently commercially available. However, in the late 1960 s and early $1970 s^{8}$, a lignin based carbon fiber was briefly commercially available by the name of Kayacarbon, produced by the Nippon Kayaku Company.

In the 1990s, there was a renewed interest in lignin-based carbon fibers ${ }^{9}$, with much of the work focused on the melt spinning method, which is simpler and less expensive than wet or dry spinning. Melt spinning requires that lignin has suitable rheology, which is determined by the level of purity and chemical structure. However, lignin can come from different biomass sources (e.g. hardwood, softwood, and grasses) and extraction methods (e.g. Kraft, organosolv, and steam explosion), meaning that lignin can be found with a diversity of purity and chemical

\footnotetext{
${ }^{2}$ Warren, C. D. "Low cost carbon fiber overview." Oak Ridge National Laboratory, Oak Ridge, Tennessee (2011). https://energy.gov/sites/prod/files/2014/03/f11/lm002_warren_2011_o.pdf (Accesses January 8th, 2017).

${ }^{3}$ Baker, Darren A., Nidia C. Gallego, and Frederick S. Baker. "On the characterization and spinning of an organicpurified lignin toward the manufacture of low-cost carbon fiber." Journal of Applied Polymer Science 124, no. 1 (2012): 227-234.

${ }^{4}$ Sudo, K., and K. Shimizu. "A new carbon fiber from lignin." Journal of applied polymer science 44, no. 1 (1992): 127-134.

${ }^{5}$ Sudo, K., K. Shimizu, N. Nakashima, and A. Yokoyama. "A new modification method of exploded lignin for the preparation of a carbon fiber precursor." Journal of applied polymer science 48, no. 8 (1993): 1485-1491.

${ }^{6}$ Warren, Charles David, Felix L. Paulauskas, Frederick S. Baker, Cliff Eberle, and Amit K. Naskar. Development of commodity grade, lower cost carbon fiber-commercial applications. Oak Ridge National Laboratory (ORNL), 2009.

${ }^{7}$ Ragauskas, Arthur J., Gregg T. Beckham, Mary J. Biddy, Richard Chandra, Fang Chen, Mark F. Davis, Brian H. Davison et al. "Lignin valorization: improving lignin processing in the biorefinery." Science 344, no. 6185 (2014): 1246843.

${ }^{8}$ Otani, S.; Fukuoka, Y.; Igarashi, B.; Sasaki, K. US Pat. 3,461,082, 1969, FR Pat. 1,458,725, (1966).

${ }^{9}$ Uraki, Y., S. Kubo, N. Nigo, Y. Sano, and T. Sasaya. "Preparation of carbon fibers from organosolv lignin obtained by aqueous acetic acid pulping." Holzforschung-International Journal of the Biology, Chemistry, Physics and Technology of Wood 49, no. 4 (1995): 343-350.
} 
structure. The implication of these variables on lignin as a carbon fiber precursor is not comprehensively known.

Technically speaking, different biomass sources will lead to lignin with different ratios of monomer units as shown in Figure 1 and interlinkages as shown in Figure 2. As a result of the extraction method, lignin will experience difference levels of fragmentation and degradation, which affects molecular weight, functional groups, condensation, intermonomer linkages, types and ratios of monomers, all of which will affect it as a carbon fiber precursor.

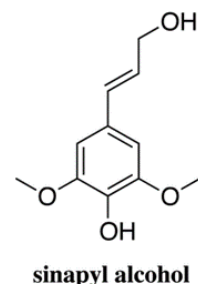

(S)

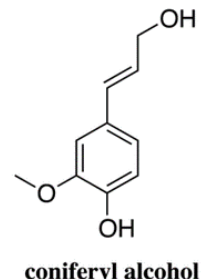

(G)

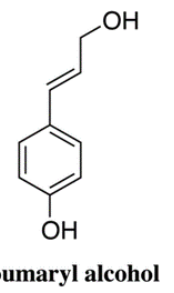

(H)

Figure 1. Three different types of monomer units in lignin.

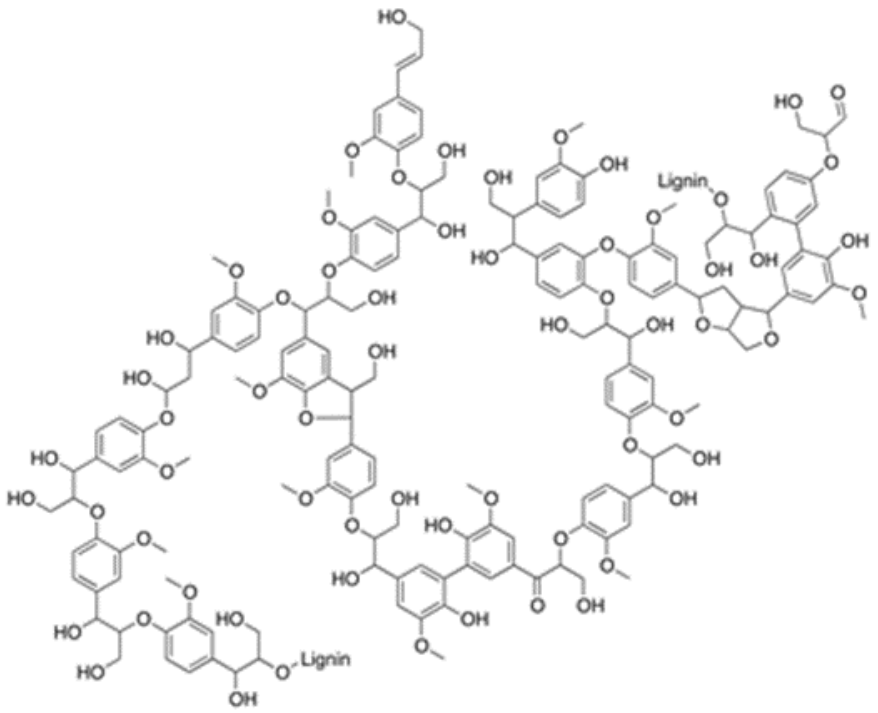

Figure 2. Example of intermonomer linkages and branching in lignin.

Generally, lignin requires some degree of modification to render it suitable for carbon fiber production. To date only relatively pure lignin from organosolv has been found to be melt spinnable with no purification, however its stabilization time was too long. Purification and/or fractionation has been reported by a number of workers ${ }^{10,11,12,13,14,15,16,17,18,19}$.

\footnotetext{
${ }^{10}$ Brodin, Ida, Marie Ernstsson, Göran Gellerstedt, and Elisabeth Sjöholm. "Oxidative stabilisation of kraft lignin for carbon fibre production. "Holzforschung 66, no. 2 (2012): 141-147.

${ }^{11}$ Norberg, Ida, Ylva Nordström, Rickard Drougge, Göran Gellerstedt, and Elisabeth Sjöholm. "A new method for stabilizing softwood kraft lignin fibers for carbon fiber production." Journal of Applied Polymer Science 128, no. 6 (2013): 3824-3830.

${ }^{12}$ Nordström, Ylva, Ida Norberg, Elisabeth Sjöholm, and Rickard Drougge. "A new softening agent for melt spinning of softwood kraft lignin." Journal of Applied Polymer Science 129, no. 3 (2013): 1274-1279.
} 
Thermal treatment of lignin such as in a vacuum or inert environment can be used to raise the glass transition temperature and lower stabilization time ${ }^{20,21,22}$, but work has not been performed to optimize the process or to investigate scale-up.

Chemical treatment is another option for modifying lignin ${ }^{23,24,25,26,27,28,29}$, for example acetylation, but concerns about the yield and other issues make chemical treatment currently less desirable to pursue as a first option than thermal treatment.

GrafTech has extensive experience and equipment for thermal and chemical treatment of carbon precursors.

Ideally, lignin-based carbon fibers would be able to match the properties of standard carbon fibers. However, this has not yet been achieved, although given the structure of lignin carbon

${ }^{13}$ Duval, Antoine, Francisco Vilaplana, Claudia Crestini, and Martin Lawoko. "Solvent screening for the fractionation of industrial kraft lignin." Holzforschung, March 2015

${ }^{14}$ Chatterjee, Sabornie, and Tomonori Saito. "Solvent Fractionation of Lignin." structure 1 (2014): 5.

${ }^{15}$ Harton, Shane E., Sai Venkatesh Pingali, Grady A. Nunnery, Darren A. Baker, S. Hunter Walker, David C. Muddiman, Tadanori Koga, Timothy G. Rials, Volker S. Urban, and Paul Langan. "Evidence for Complex Molecular Architectures for Solvent-Extracted Lignins." ACS Macro Letters 1, no. 5 (2012): 568-573.

${ }^{16} \mathrm{Li}$, Hui, and Armando G. McDonald. "Fractionation and characterization of industrial lignins." Industrial Crops and Products 62 (2014): 67-76.

${ }^{17}$ Strassberger, Z. et al.; Lignin solubilisation and gentle fractionation in liquid ammonia, Green Chemistry 17 (2015). - ISSN 1463-9262 - p. 325 - 334

${ }^{18}$ Saito, Tomonori, Joshua H. Perkins, Frederic Vautard, Harry M. Meyer, Jamie M. Messman, Balazs Tolnai, and Amit K. Naskar. "Methanol fractionation of softwood kraft lignin: impact on the lignin properties." ChemSusChem 7, no. 1 (2014): 221-228.

${ }^{19}$ Bahl O P, Shen Z, Lavin J G and Ross R A. (1998). Manufacture of carbon fibers. In Carbon Fibers Ed(s). Donnet J-B, Wang T K, Peng J C M and Reboulliat S, Marcel Dekker, New York, pp. 1-83.

${ }^{20}$ Baker, Darren A [ORNL]; Baker, Frederick S [ORNL]; Gallego, Nidia C [ORNL], Thermal Engineering of Lignin for Low-cost Production of Carbon Fiber, Conference: The Fiber Society Fall Technical Conference 2009, Athens, GA, USA, 20091027, 20091030

${ }^{21}$ Kadla, John F., Satoshi Kubo, Richard D. Gilbert, and Richard A. Venditti. "Lignin-based carbon fibers." In Chemical Modification, Properties, and Usage of Lignin, pp. 121-137. Springer US, 2002.

${ }^{22}$ Kadla, J. F., S. Kubo, R. A. Venditti, R. D. Gilbert, A. L. Compere, and W. Griffith. "Lignin-based carbon fibers for composite fiber applications." Carbon 40, no. 15 (2002): 2913-2920.

${ }^{23}$ Chatterjee, Sabornie, Eric B. Jones, Amy C. Clingenpeel, Amy M. McKenna, Orlando Rios, Nicholas W. McNutt, David J. Keffer, and Alexander Johs. "Conversion of lignin precursors to carbon fibers with nanoscale graphitic domains." ACS Sustainable Chemistry \& Engineering 2, no. 8 (2014): 2002-2010.

${ }^{24}$ Thunga, Mahendra, Keke Chen, David Grewell, and Michael R. Kessler. "Bio-renewable precursor fibers from lignin/polylactide blends for conversion to carbon fibers." Carbon 68 (2014): 159-166.

${ }^{25}$ Monteil-Rivera, Fanny, and Louise Paquet. "Solvent-free catalyst-free microwave-assisted acylation of lignin." Industrial Crops and Products (2014).

${ }^{26}$ Zhang, Meng, and Amod A. Ogale. "Carbon fibers from dry-spinning of acetylated softwood kraft lignin." Carbon 69 (2014): 626-629.

${ }^{27}$ Kubo, S., and J. F. Kadla. "Lignin-based carbon fibers: Effect of synthetic polymer blending on fiber properties." Journal of Polymers and the Environment 13, no. 2 (2005): 97-105.

${ }^{28}$ Sevastyanova, Olena, Wei Qin, and J. F. Kadla. "Effect of nanofillers as reinforcement agents for lignin composite fibers." Journal of applied polymer science 117, no. 5 (2010): 2877-2881.

${ }^{29}$ Qin, W., and J. F. Kadla. "Effect of organoclay reinforcement on lignin-based carbon fibers." Industrial \& Engineering Chemistry Research 50, no. 22 (2011): 12548-12555. 
fibers seen to date functional properties such as thermal insulation or filtration appear to have the most promise as an entry point for commercialization and the building up of a supply chain.

Motivating factors for lignin-based carbon fibers include: (1) filling in the gap on alternatives to petroleum-based carbon fibers, (2) finding renewable precursors that are decoupled from petroleum, and (3) reducing cost, energy expenditure, and $\mathrm{CO}_{2}$ emissions versus petroleum.

As a carbon fiber precursor, however, there are unique challenges with lignin. The diverse chemical structure of lignin complicates its conversion into carbon fiber. Lignin is not a waste product and high purity and high quality comes at a cost. There are no universally adopted standard test methods for characterizing lignin unambiguously, and complete characterization is beyond current methods.

Despite the challenges, the literature shows much progress has been made in modifying lignin to make it more suitable as a precursor, however scalable methods are needed for commercial viability.

In addition to the identification of scalable methods for producing lignin with specific technical characteristics, applications must be validated to complete the supply chain. Given the chemical structure of lignin, energy applications could be a viable commercial entryway. 


\section{TECHNICAL DISCUSSION OF WORK PERFORMED}

The main accomplishments in this research are summarized in the following list, with further details provided in the paragraphs below.

1. High purity lignin (ash $<0.25 \%$ ) from hardwood, softwood, and grass biomass was melt spun into single filament fiber of acceptable quality

2. Melt spun lignin fibers were stabilized in an acceptable time period (time $<4$ hours), through use of a chemical treatment, with several showing stabilization times under 2.5 hours

3. Lignin fiber was carbonized with acceptable yield $>40 \%$

- Lignin and lignin fiber was characterized for ash level, surface area, density, and diameter

4. A cost model was developed to quantify the effect and sensitivity of lignin precursor cost, stabilization time, and carbonization yield on estimated LBCF production cost

- The cost model was then expanded to include potential energy reduction (savings) and $\mathrm{CO}_{2}$ avoidance

5. Progress was made towards establishing a LBCF supply chain, with multiple lignin sources

This project focused on the melt processing path of lignin conversion, as illustrated in Figure 3.

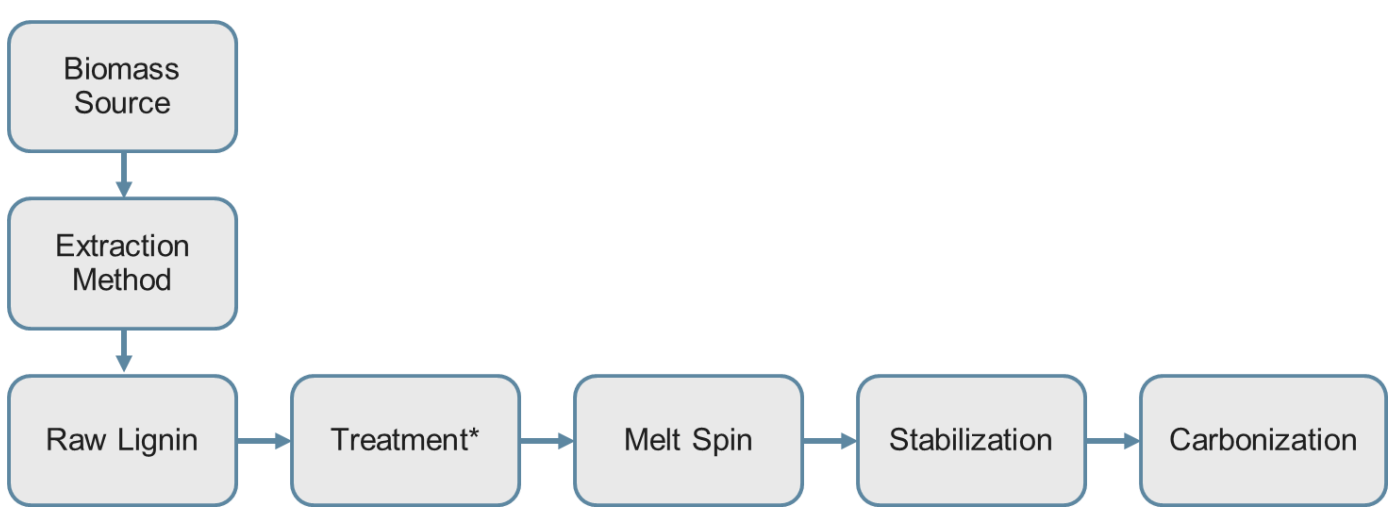

Figure 3. Flow chart of lignin conversion.

The first accomplishment was that high purity lignin from hardwood, softwood, and grass biomass (produced by GTI) was able to be melt spun into single filament fiber of acceptable quality (task conducted at ORNL). The first part of this accomplishment was to identify suitable lignin sources, which are shown in Table 2, which represent a range of established and emerging lignin sources. It is important to note that the selected range of lignin represents different biomass types (hardwood, softwood, and grass) and different lignin extraction methods (Kraft, organosolv, steam explosion), which is important as a supply chain must have this type of diversity in availability. The second part of this accomplishment was to demonstrate rapid 
methods of evaluating melt spinnability. This involved purity testing, melting temperature range measurement, and single fiber melt spinning. These were used as criteria for down selecting lignin from the original list to focus only on the most promising lignin sources for continuing work. It has been shown that water washing and solvent extraction has potential for reaching the purity levels required in the final LBCF.

The second accomplishment was to demonstrate that melt spun lignin fibers were able to be stabilized in an acceptable time period (time $<4$ hours), particularly through the use of a physical modification. The lignin modification is both low cost and scalable, which are crucial characteristics in order to justify moving forward. It was found that without the modification, lignin fibers were not able to pass the 4-hour stabilization time. Microscopic images of the stabilized lignin fibers are shown in Figure $\mathbf{4}$ demonstrating the fibers maintained their integrity and form during stabilization. Proper stabilization of the fibers is crucial, as fibers that exhibit too much fusion during stabilization will not be able to be carbonized and milled.

Table 2: Table of lignin samples.

\begin{tabular}{|l|l|l|l|l|}
\hline ID & \multicolumn{1}{|c|}{ Lignin Supplier } & \multicolumn{1}{|c|}{ Lignin Sample ID } & \multicolumn{1}{c|}{ Biomass Type } & \multicolumn{1}{c|}{ Isolation Method } \\
\hline 1 & Gryphin Elements & HW organosolv & Hardwood & Organosolv \\
\hline 2 & Borregaard LignoTech & Marasperse CBOS-4 & Lignosulfonate & Lignosulfonate \\
\hline 3 & Borregaard LignoTech & Ultrazine NA & Lignosulfonate & Lignosulfonate \\
\hline 4 & MeadWestvaco & Indulin AT & Softwood & Kraft \\
\hline 5 & Green Value & Protobind 1000 & Wheatstraw & Soda \\
\hline 6 & Green Value & Protobind 2000 & Wheatstraw & Soda \\
\hline 7 & Green Value & Protobind 2400 & Wheatstraw & Soda \\
\hline 8 & Green Value & Protobind 3000 & Wheatstraw & Soda \\
\hline 9 & Green Value & Protobind 4000 & Wheatstraw & Soda \\
\hline 10 & Green Value & Protobind 6000 & Wheatstraw & Soda \\
\hline 11 & Stora Enso & Bagasse & Bagasse & Kraft \\
\hline 12 & Sunstrand & Bamboo & Bamboo & Kraft \\
\hline 13 & TennEra & TennEra & Switchgrass & Organosolv \\
\hline 14 & Fibria & Eucalyptus organosolv & Eucalyptus & Organosolv \\
\hline 15 & Cedar Creek P\&T & Cedar Creek & Hardwood & Steam explosion \\
\hline
\end{tabular}




\section{Microscopy of Stabilized Fibers at Lab Scale}

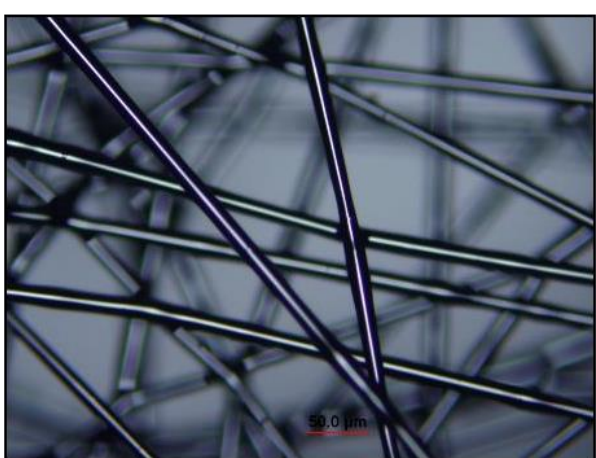

HW organosolv -3 hours

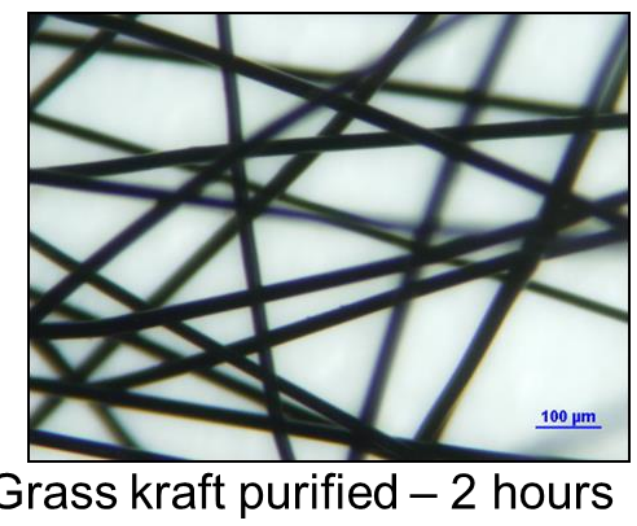

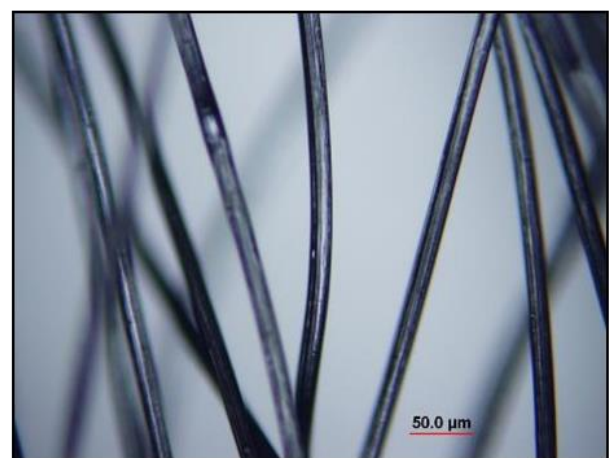

Softwood kraft purified -1.5 hours

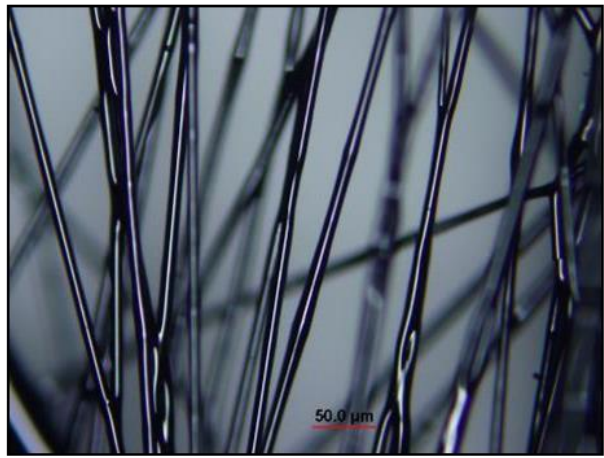

Lignin \#DD - 2.5 hours

Figure 4: Stabilized lignin fibers samples. Images taken by GrafTech.

The third accomplishment was to demonstrate that the lignin had an acceptable carbonization yield. Without an acceptable yield, the economics of LBCF production will not work. It was found that the LBCF evaluated all had greater than $40 \%$ yield, which is acceptable for continuing development studies, although further optimization is necessary. In addition, it was demonstrated that select carbonized LBCF could be milled (chopped) into small discontinuous fibers of the kind that are desired for fabricating high-temperature rigid insulation. This is an important finding, and future work will focus on determining the degree to which lignin can fuse during stabilization and still be carbonized and milled into fiber. Photomicrographs of milled LBCF produced are shown in Figure 5. 


\section{Microscopy of Carbonized and Milled Fibers at Lab Scale}

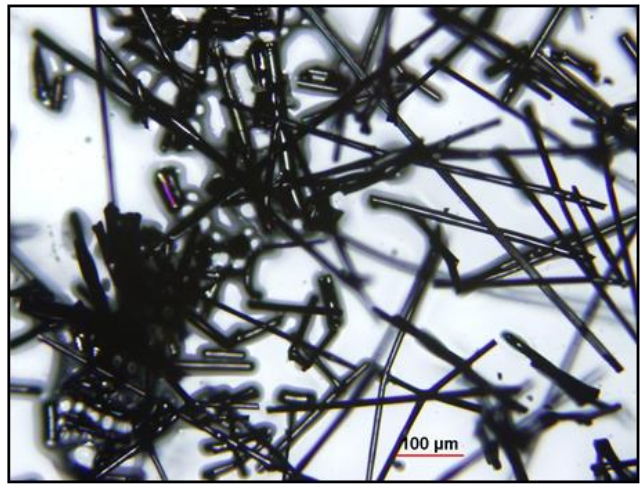

Hardwood organosolv

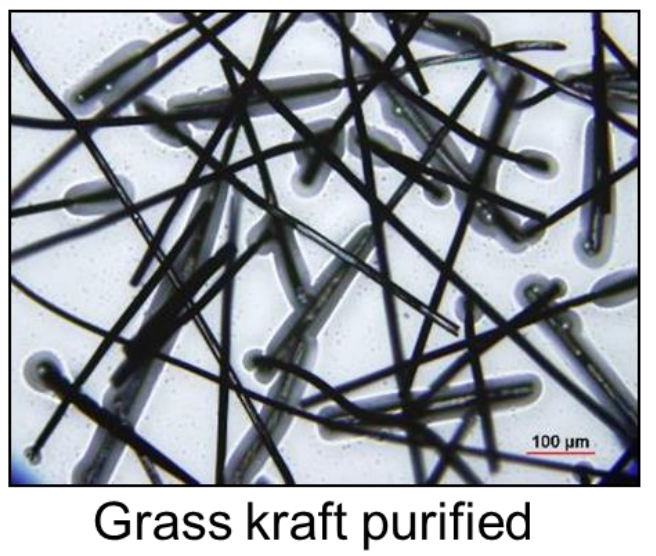

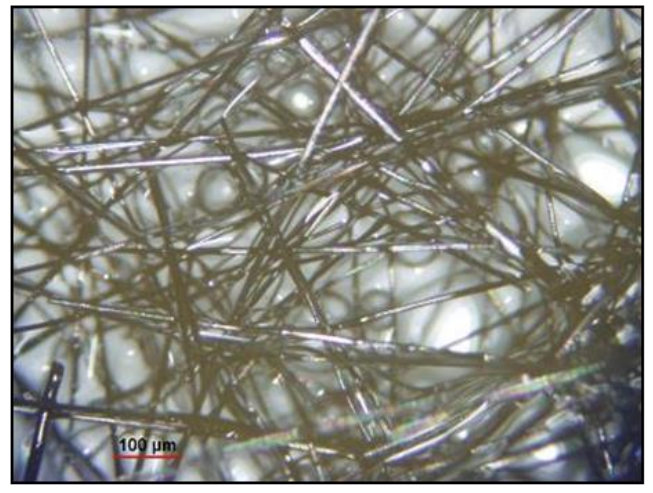

Softwood kraft purified

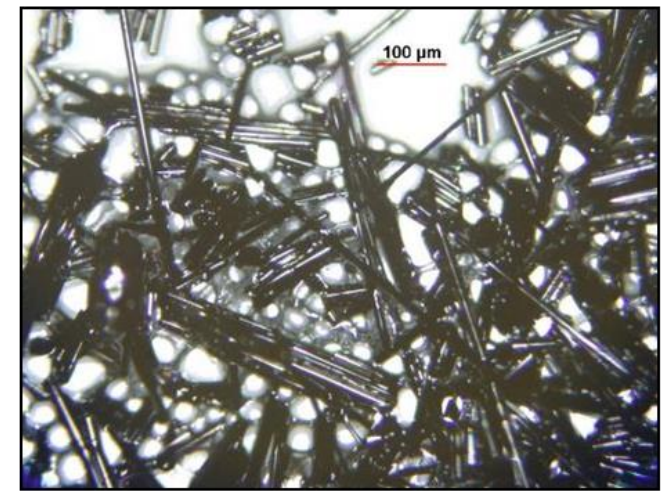

Lignin \#DD

Figure 5: Carbonized and milled (chopped) LBCF from two different types of lignin. Images taken by GrafTech.

The fourth accomplishment was the development of a cost model. The model was based on publicly available data from Harper International and ORNL ${ }^{30,31,32,33,34}$, and compiled by GTI. A comparison of the previous and new model is shown in Figure 6. The previous model was published in ORNL/TM-2013/54 ${ }^{1}$. One main difference is that the previous model assumed

\footnotetext{
${ }^{30}$ Non-Traditional Precursor Materials and Conversion Approaches for Lower Cost Carbon Fiber for Multiple Industries, C. David Warren, Felix L. Paulauskas, C. Cliff Eberle, Amit K. Naskar, and Soydan Ozcan, Oak. The Seventeenth Annual International Conference on Composites/Nano Engineering (ICCE - 17) July 26-31, 2009 in Hawaii, USA

${ }^{31}$ Paulaskas, FL. "Novel Precursor materials and approaches for producing lower cost carbon fiber for high volume industries." Automotive Applications \& Recycling, Edimburgo,[sn] (2009).

${ }^{32}$ Das, Sujit. "Life cycle assessment of carbon fiber-reinforced polymer composites." The International Journal of Life Cycle Assessment 16, no. 3 (2011): 268-282.

${ }^{33}$ Cost Modeling of Alternative Carbon Fiber Manufacturing Technologies - Baseline Model Demonstration, Sujit Das, Josh Warren, DOE Meeting, Washington, DC, Apr 52012

${ }^{34}$ Friedfeld, Barry, "Cost Assessment of Lignin-and PAN-Based Precursor for Low-Cost Carbon Fiber", Presentation for the Automotive Composites Consortium, 17 January 2007
} 
lignin purchase price of $\$ 0.25 / \mathrm{lb}$., while the new model assumes $\$ 0.50 / \mathrm{lb}$. The new cost model quantified the effect of lignin precursor cost, stabilization time, and carbonization yield on estimated carbon fiber production cost, and also confirmed that these three variables have the largest effect, as shown in Figure 7. A sensitivity plot showing the significance of these three variables in shown in Figure 8, specifically highlighting the large effect that carbon yield, precursor cost, and stabilization time have on the estimated production cost. Therefore, current and future technical work must optimize these variables.

The baseline model shown in Figures 6-8 assumes the following, which meet the $\$ 5.00 / \mathrm{lb}$ target.

- Lignin purchase price of $\$ 0.50 / \mathrm{lb}$.

- Lignin modification cost of $\$ 0.20 / \mathrm{lb}$.

- Lignin melt blowing cost of $\$ 0.88 / \mathrm{lb}$.

- Lignin fiber stabilization time of 2 hours

- Lignin fiber carbonization yield of $45 \%$

- Lignin sizing and surface treatment are not needed

- Lignin emissions abatement cost of $\$ 0.04 / \mathrm{lb}$.

- Lignin packaging cost of $\$ 0.25 / \mathrm{lb}$.

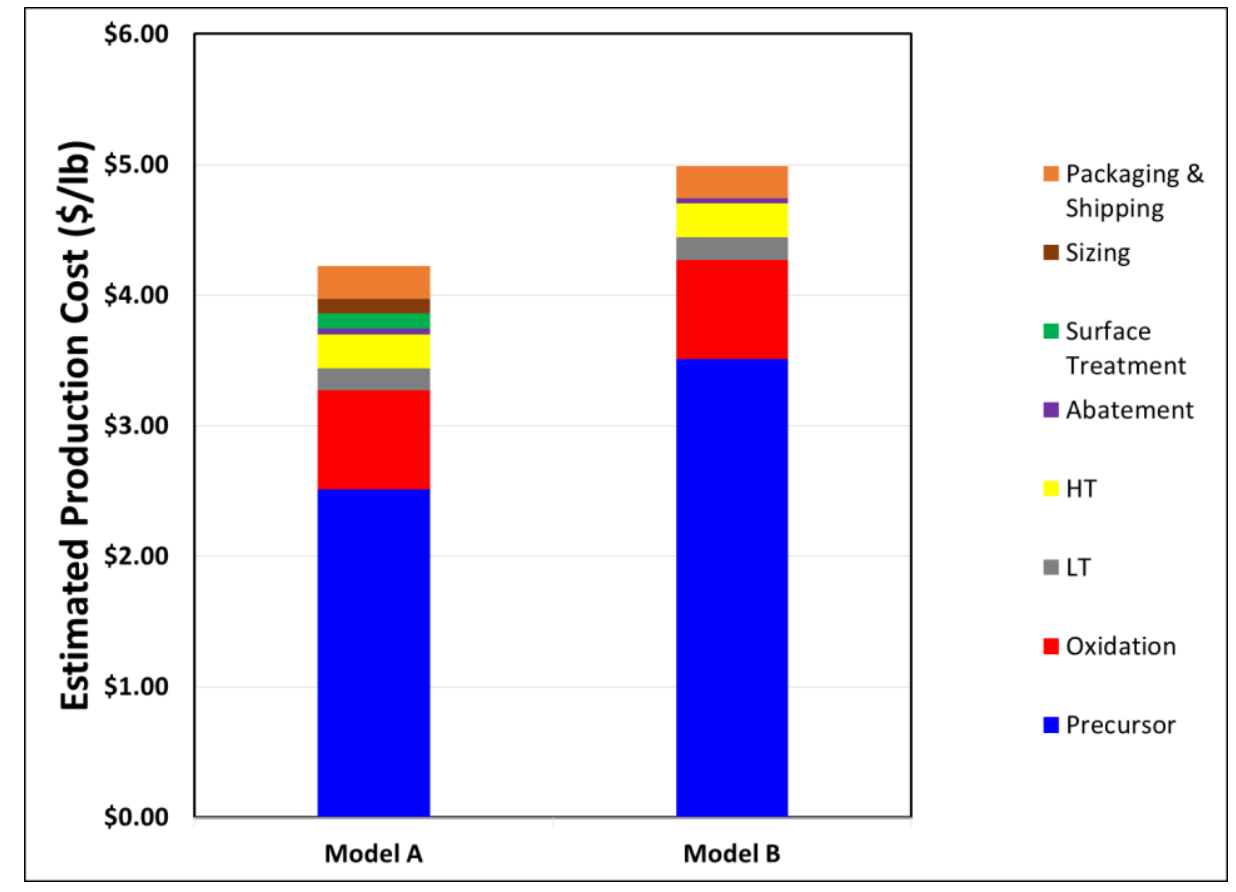

Figure 6: Chart compares two lignin-based carbon fiber cost models. Model A is original ORNL cost model as described in ORNL/TM-2013/54. Model B is cost model updated by GrafTech. In this chart the precursor costs include lignin, lignin treatment, and melt blowing. 


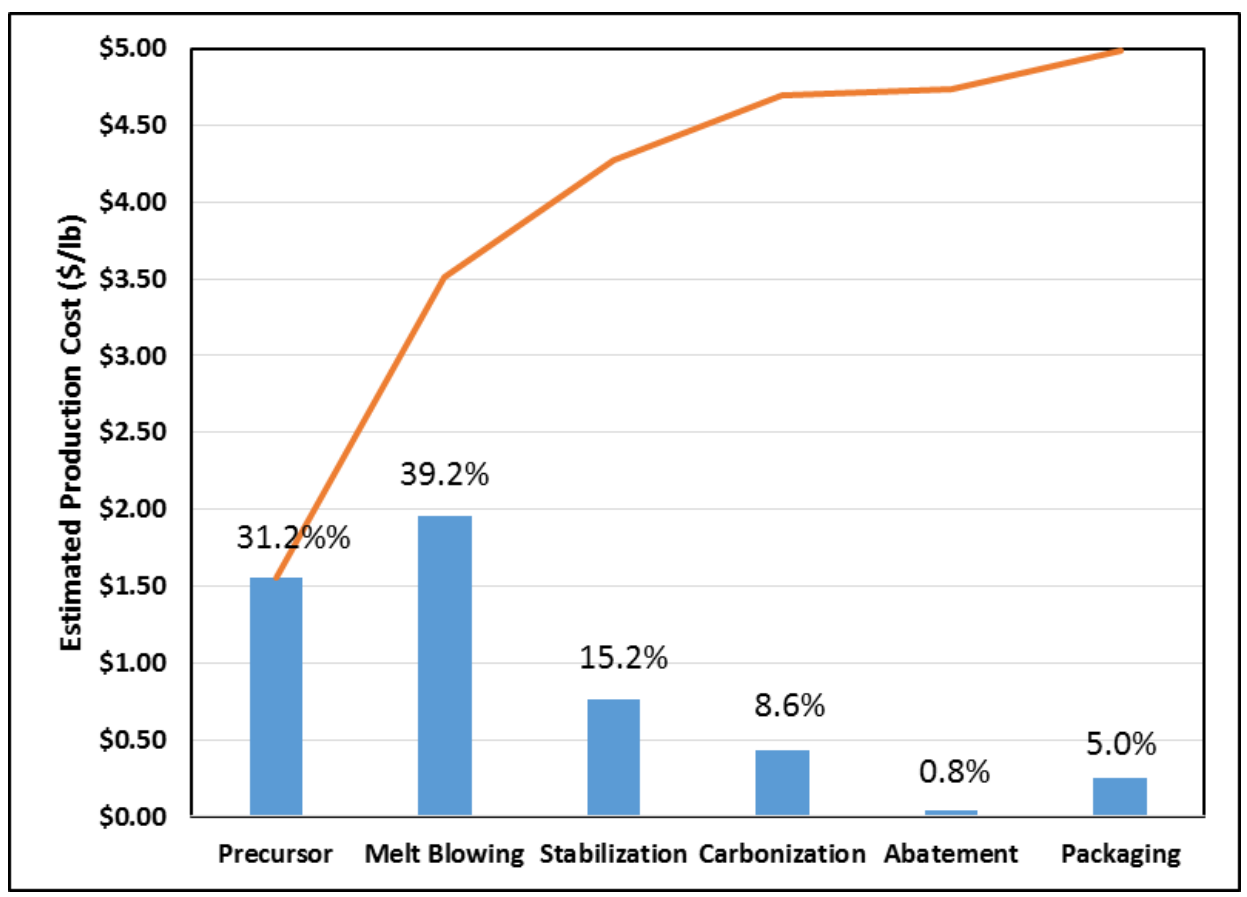

Figure 7: Chart demonstrates the predicted contribution of each processing step in LBCF to total estimated production cost.

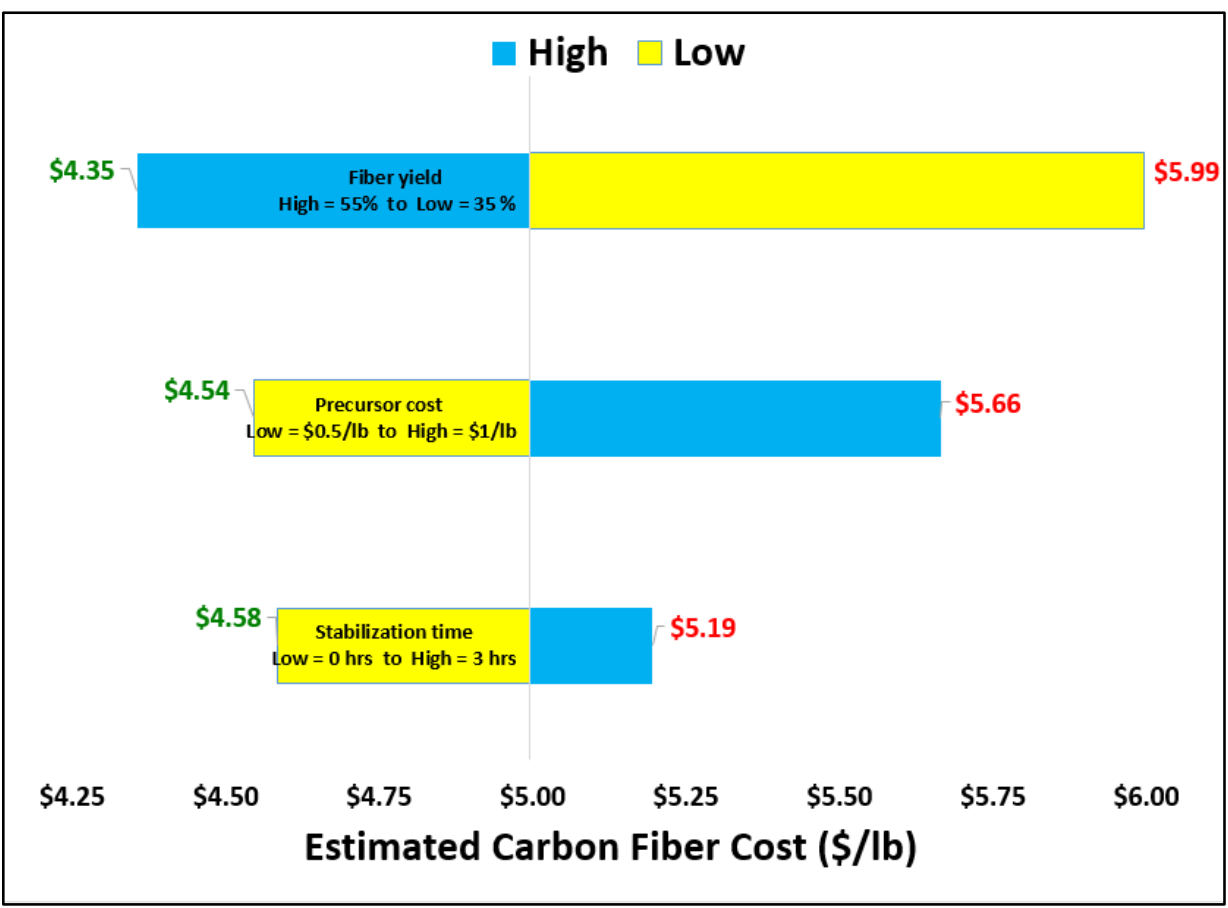

Figure 8: Predicted sensitivity from cost model of fiber carbonization yield, precursor cost, and stabilization time. The midpoint is $\$ 5.00 / \mathrm{lb}$, and the size of the bars indicates that when taken by itself fiber yield has the largest relative effect, with precursor cost being the second largest effect, and stabilization time being the third. 
The model can be used to show which combination of lignin precursor cost, stabilization time, and carbonization yield will meet the $\$ 5.00 / \mathrm{lb}$. cost target. The model also shows how reducing stabilization time would allow a higher cost of lignin precursor, to permit modifications or treatments, as shown in Figure 9. The blue box in Figure 9 highlights the region of interest for this project, which will achieve less than $\$ 5.00 / \mathrm{lb}$. estimated production cost assuming a carbon yield of $45 \%$. In particular, for every 2 hours that stabilization time can be reduced, the model can permit $\$ 0.25 / \mathrm{lb}$. in additional cost in lignin (likely cost of plasticizers or thermal/chemical modification). Therefore, within reason, cost model shows treatments can be performed that increase lignin price as long as they reduce stabilization time by the above ratio, and still meet estimated $\$ 5.00 / \mathrm{lb}$. production cost. A higher carbon yield would further improve the economics. This model will continue to be used and refined. Figure 10 shows the breakdown of the cost model for the 4 down selected lignin samples.

The fifth accomplishment was to demonstrate progress towards establishing a lignin-based carbon fiber supply chain. The first step in establishing the supply chain was to survey the landscape of existing lignin producers and evaluate the lignin they had commercially available. This step immediately eliminated lignin sources that had ash levels above 5\% since these were not pure enough to be melt spun and it would be too inefficient to remove ash above $5 \%$ in a separate purification step. However, there were sufficient established or emerging lignin suppliers that could produce high purity lignin and these were the focus. The LignoBoost ${ }^{35,36}$ and LignoForce ${ }^{37}$ processes are the only industrial scale lignin extraction processes currently in use. There are pilot scale organosolv and stream explosion lignin extraction in the USA. There are several lignin suppliers in the USA, including Ingevity (formerly MeadWestvaco), Green Value, and Domtar. In addition, there is West Fraser in Canada and Stora Enso in Finland. Also, there are several emerging lignin suppliers with pilot plant capability in the United States, including Stora Enso (formerly Virdia), Renmatix, Cedar Creek P\&T, and TennEra, and these could become full industrial scale in a few years.

\footnotetext{
${ }^{35}$ Tomani, Per. "The lignoboost process." Cellulose Chemistry \& Technology 44.1 (2010): 53.

${ }^{36}$ Zhu, Weizhen, Gunnar Westman, and Hans Theliander. "Investigation and characterization of lignin precipitation in the lignoboost process." Journal of Wood Chemistry and Technology 34.2 (2014): 77-97.

${ }^{37}$ Kouisni, Lamfeddal, et al. "LignoForce System for the Recovery of Lignin from Black Liquor: Feedstock Options, Odor Profile, and Product Characterization." ACS Sustainable Chemistry \& Engineering 4.10 (2016): 5152-5159.
} 


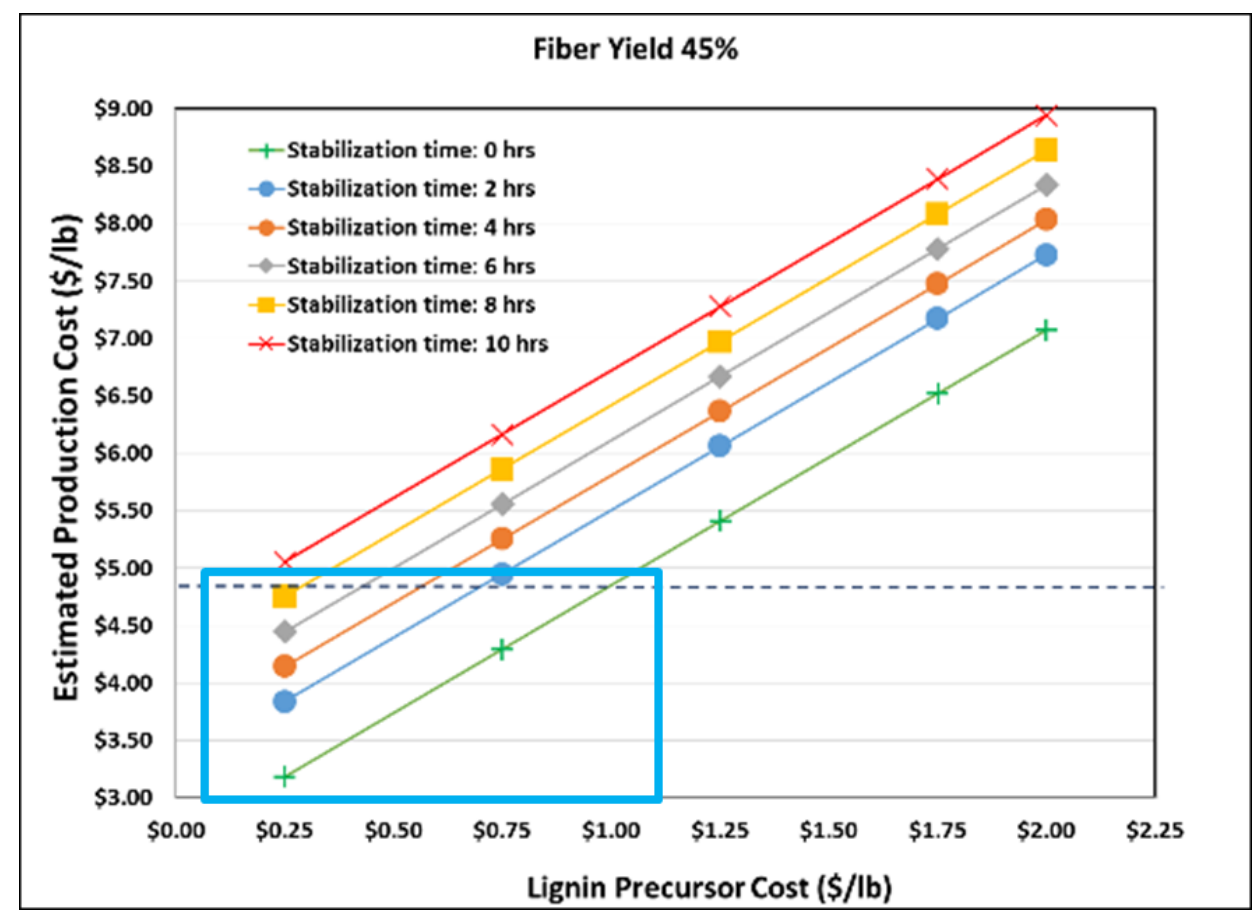

Figure 9: Predicted effect from cost model showing influence of stabilization time. Plot shows predicted effect from cost model of stabilization time, assuming $45 \%$ carbon yield. The blue box shows the range of conditions to meet $\$ 5.00 / \mathbf{l b}$ estimated production cost. 


\begin{tabular}{|c|c|c|c|c|}
\hline $\begin{array}{l}\overline{\bar{g}} \\
\stackrel{0}{0}\end{array}$ & $\begin{array}{l}\text { g } \\
\text { d. } \\
\text {. }\end{array}$ & $\begin{array}{l}8 \\
\text { 虫 }\end{array}$ & $\begin{array}{l}8 \\
\text { 岗 }\end{array}$ & $\begin{array}{l}\text { क् } \\
\text { d. }\end{array}$ \\
\hline 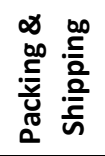 & $\begin{array}{l}\stackrel{\sim}{n} \\
\stackrel{\leftrightarrow}{n}\end{array}$ & $\begin{array}{l}\text { N్ } \\
\text { in. }\end{array}$ & $\begin{array}{l}\stackrel{\sim}{\sim} \\
\stackrel{\leftrightarrow}{n}\end{array}$ & 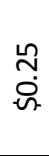 \\
\hline 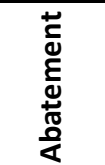 & $\begin{array}{l}\text { du } \\
\text { o. }\end{array}$ & $\begin{array}{l}\text { Dे } \\
\text { Q. }\end{array}$ & $\begin{array}{l}\text { do } \\
\text { D. }\end{array}$ & $\begin{array}{l}\text { Do } \\
\text { o. }\end{array}$ \\
\hline 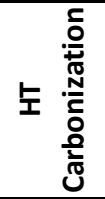 & $\begin{array}{l}\stackrel{D}{1} \\
\stackrel{2}{0}\end{array}$ & $\begin{array}{l}\stackrel{0}{1} \\
\text { S. }\end{array}$ & $\begin{array}{l}\text { D. } \\
\text { in }\end{array}$ & $\begin{array}{l}\stackrel{D}{1} \\
\text { ¿̊. }\end{array}$ \\
\hline 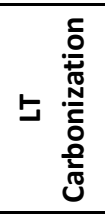 & $\begin{array}{l}\text { ने } \\
\text { o. }\end{array}$ & $\begin{array}{l}\text { ने } \\
\text { in }\end{array}$ & $\begin{array}{l}\text { f) } \\
\text { s. }\end{array}$ & $\begin{array}{l}\text { ने } \\
\text { in }\end{array}$ \\
\hline 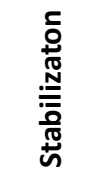 & $\begin{array}{l}\text { o } \\
\text { o. }\end{array}$ & $\begin{array}{l}\stackrel{\Omega}{0} \\
\dot{Q}\end{array}$ & $\begin{array}{l}\hat{N} \\
\text { o. }\end{array}$ & 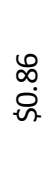 \\
\hline 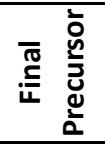 & $\begin{array}{l}\vec{m} \\
\ddot{n}\end{array}$ & $\begin{array}{l}\vec{\Delta} \\
\dot{\omega}\end{array}$ & $\begin{array}{l}\text { 员 } \\
\stackrel{0}{*}\end{array}$ & $\begin{array}{l}\infty \\
\tilde{m} \\
\ddot{*}\end{array}$ \\
\hline 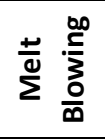 & $\begin{array}{l}\infty \\
\infty \\
\stackrel{0}{0}\end{array}$ & $\begin{array}{l}\infty \\
\infty \\
\stackrel{\infty}{*}\end{array}$ & $\begin{array}{l}\infty \\
\infty \\
\stackrel{0}{*} \\
0\end{array}$ & $\begin{array}{l}\infty \\
\infty \\
\stackrel{0}{0} \\
\text {. }\end{array}$ \\
\hline 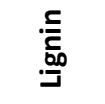 & $\begin{array}{l}\stackrel{\infty}{0} \\
\stackrel{0}{0}\end{array}$ & $\begin{array}{l}\vec{b} \\
\dot{0}\end{array}$ & $\begin{array}{l}\vec{b} \\
\dot{0} \\
\text { or }\end{array}$ & $\begin{array}{l}\text { : } \\
\text { in }\end{array}$ \\
\hline 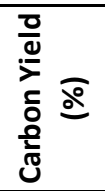 & $\begin{array}{l}\text { 今े } \\
\dot{y}\end{array}$ & $\begin{array}{l}\text { 今े } \\
\dot{\sigma}\end{array}$ & ذें & $\begin{array}{l}\stackrel{\circ}{\circ} \\
\dot{j}\end{array}$ \\
\hline 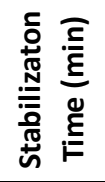 & $\underset{\sim}{\mathbb{D}}$ & $\hat{\infty}$ & $\stackrel{ }{g}$ & 乌ㄱㅁ \\
\hline 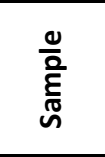 & 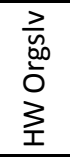 & 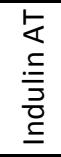 & $\begin{array}{l}8 \\
0 \\
0 \\
\ddot{0} \\
0\end{array}$ & ฉิ \\
\hline$\underline{\underline{a}}$ & $r$ & $\sigma$ & in & ฉิ \\
\hline
\end{tabular}

Figure 10: Cost model breakdown 


\section{SUBJECT INVENTIONS}

The following invention has been made from this research:

\begin{tabular}{|c|c|}
\hline $\begin{array}{l}\text { ORNL } \\
\text { ID-3682 }\end{array}$ & $\begin{array}{l}\text { Modification of Lignin and Fibers Made Thereby } \\
\text { Lignin material from a specific biomass source and associated extraction or } \\
\text { isolation process can be applied with a universal treatment to obtain a low- } \\
\text { cost formulation that can be processed into fiber; these fibers can then be } \\
\text { dimensionally stabilized without inter-filament fusion. In some } \\
\text { embodiments where the fibers are used in carbon fiber manufacturing the } \\
\text { stabilization time can be significantly minimized. These fibers will then be } \\
\text { carbonized to obtain carbon fibers. The method was found to be applicable } \\
\text { for all lignins known in the art (hardwood, softwood, grass, and other } \\
\text { derivatized lignins). However, depending on the source of lignin the } \\
\text { formulation or the composition can be modified without altering the } \\
\text { chemistry. This makes the approach lignin source-neutral. }\end{array}$ \\
\hline
\end{tabular}




\section{COMMERCIALIZATION POSSIBILITIES}

Lignin is a byproduct of pulp and papermaking as well as biorefining ${ }^{38,39,40}$. Currently approximately 50 million metric tonnes (MT) of lignin is produced, but most of it is consumed as a fuel for burning. However, lignin is also used in higher value applications, which are growing. For example, lignin is used in dispersants, binders, adhesives, and emulsifying agents. In addition, lignin has seen use in animal feed, dust control, and concrete. Lignosulfonates are the main lignin product, with 1.1 MT produced in 2013.

A small but growing segment of lignin is for higher value applications like carbon fiber, which requires an "engineered" lignin. In order for the amount of higher value "engineered" lignin to increase in production and availability, there must be demand from end use applications. Given the state of current lignin technology, functional carbon fibers (i.e. non structural) appear to be the most appropriate commercial entryway. This work was initiated towards that end, and it is expected that the work completed in this project will further the state of the art of lignin technology and contribute to future projects that seek to develop lignin fibers and demonstrate in commercial applications.

Specifications for lignin will need to be developed that are application specific. For example, insulation applications will need low thermal conductivity while filtration applications will need high surface area and adsorption properties.

\footnotetext{
${ }^{38}$ NNFCC Renewable Chemicals Factsheet: Lignin

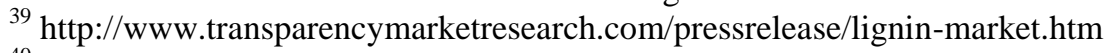

${ }^{40}$ Grand View Research, Inc., Lignin Market Analysis By Product (Low-Purity Lignin, Ligno-Sulphonates, Kraft Lignin) By Application (Macromolecules, Aromatics) And Segment Forecasts To 2022, http://www.grandviewresearch.com/industry-analysis/lignin-market

Transparency Market Research, Lignin Market - Global Industry Analysis, Size, Share, Growth, Trends and Forecast, 2015 - 2023,
} 


\section{PLANS FOR FUTURE COLLABORATION}

The work that has been completed is a significant step towards the commercialization of lignin carbon fiber technology.

GrafTech and ORNL will continue to seek opportunities where their individual core strengths overlap and can collaborate to develop and demonstrate advanced technology and further the mission of the US DOE. 


\section{CONCLUSIONS}

1. The worked performed by GrafTech, under DE-EE0005779, and ORNL, under CRADA No. NFE-15-05807, helped to advance the state of the art of lignin technology as it relates to its conversion to carbon fiber for functional applications, although the TRL remained at 5 .

2. Specifically, the low-cost lab-scale lignin modifications developed in this project were shown to reduce thermal stabilization time to levels not seen before, and as expected were found to work within different degrees depending on the type of biomass. Thermal stabilization time is one of the larger cost drivers, and reducing stabilization time at the lab-scale to be on the order of a few hours, is a significant accomplishment.

3. The modifications were found to be applicable to hardwood, softwood, and grass lignin types, although the degree of success is intrinsic to the chemical makeup of each lignin type, which was expected and opened the door to further optimizing the modification recipes for each lignin type.

4. The lignin modifications were estimated to be low cost and scalable, which are some of the main considerations for production.

5. The overall cost model for the different modified lignin types (at the lab scale) showed the project met the initial goal of $\$ 5.00$ /pound estimated production cost but would need to be validated at a larger scale in order to assess commercial viability.

6. Scalability is an important consideration for any lignin method, and eliminated many of the modification methods reported in the literature due to their prohibitive cost. The cost of many reported modifications is not well known, nor is the cost of achieving specific technical specifications for "engineered" lignin.

7. Collaboration needs to take place between lignin producers, product manufacturers, and end users in order to establish a supply chain that validates lignin viable for specific commercial applications.

8. It is expected that there will need to be specifications for lignin for each application type, as different functional applications will have different requirements. For example, insulation applications will prioritize low thermal conductivity while filtration applications will prioritize high surface area and adsorption properties. 